\title{
Learning from adverse treatment effects
}

Neurol Neuroimmunol Neuroinflamm November 2019 vol. 6 no. 6 e630. doi:10.1212/NXI.0000000000000630

The diagnosis and treatment of patients with adverse side effects of therapy can be challenging. Part of this challenge is staying up to date on the potential adverse effects associated with the increasingly numerous and complex treatments available. Among the excellent studies in the November issue of N2, there are several that address this issue.

Immune-related adverse events associated with immune checkpoint inhibitors (ICIs) are increasingly recognized and often affect the nervous system. In the study by Vogrig et al., ${ }^{1}$ the authors retrospectively reviewed a cohort of 50 patients with anti-Ma2 paraneoplastic neurologic syndrome and identified 6 that developed the syndrome after treatment with ICI. There were no differences between the neurologic syndromes and paraclinical features of these 6 patients compared with the other anti-Ma2 cases. However, none of the 6 patients had testicular cancer, which was found in $25 \%$ of the rest of the cohort. All 6 patients received treatment aimed at the neurologic syndrome including withdrawal of the ICIs and steroids, and for some patients, plasmapheresis or rituximab. Four of the patients died, and the other 2 had moderate to severe disability. The cause of death was directly attributed to the neurologic disease and associated complications in 3 patients. During the 12-month period in which the 6 patients with ICIassociated anti-Ma2 cases were identified, a total of 17 patients were diagnosed with anti-Ma2 syndrome. Before this, the annual number of anti-Ma2 cases diagnosed in this reference center was relatively stable with a median of 4 cases per year. Although the study does not provide the time from onset of neurologic symptoms to recognition of the anti-Ma2 syndrome and treatment, it is possible that earlier recognition and intervention could have improved the outcome. Although there was a general increase in the number of patients with anti-Ma2 syndrome identified by the authors, it is remarkable that almost $1 / 3$ had treatments with ICIs. The finding suggests that we should expect an increase of other paraneoplastic neurologic syndromes as these drugs become increasingly available for a wide variety of cancers.

Progressive multifocal leukoencephalopathy (PML) is caused by reactivation of the JC virus and occurs primarily in patients with innate immunodeficiency or taking immunosuppressants. To characterize the risk factors, clinical course and treatment of patients with PML, Dr. Anand et al. ${ }^{2}$ examined a retrospective cohort of 91 patients with confirmed PML seen at 2 institutions over a 25-year period. HIV infection was the most common risk factor and was identified in almost half of the cases. Other frequent risk factors were hematologic malignancy or myelodysplasia, use of chemotherapy, and use of monoclonal antibody therapies, which represented $19 \%$ of cases. Some patients had more than 1 risk factor such as malignancy and chemotherapy exposure or a rheumatologic disease and treatment with immunosuppressants. The most common presenting symptoms were hemiparesis and gait and speech abnormalities, but close to a third of patients had other presenting symptoms. The authors describe the risk factors separated over 4 year periods, demonstrating the changing pattern of risk factors that practitioners need to be aware of. Treatment options for PML are limited. Withdrawal of immunosuppressive medication, when applicable, and combined antiretroviral therapy (cART) in patients with HIV have 
been the 2 main approaches that sometimes offer some benefit. In this study, the median survival of the patients with HIVassociated PML was significantly longer compared with that of patients without HIV, and all 10-year survivors were patients with HIV who were treated with cART. Recently, there have been a few reports of good outcomes of HIV- and non-HIVassociated PML with the use of ICIs. The possibility of an effective therapy for PML makes increasingly important that patients are diagnosed promptly. In this issue of N2, 2 case reports of PML showing absolutely no benefit of an ICI (pembrolizumab) and an editorial comment by Dr. Du Pasquier provide an interesting perspective on this topic. ${ }^{3-5}$

Dr. Turner et al. ${ }^{6}$ report a patient who acutely developed selective pigmented hair loss while being treated with intravenous immunoglobulin (IVIg). The patient had recently developed severe pandysautonomia in association with ganglionic AChR antibodies after an infectious illness. Before treatment with IVIg, he had mixed black and white hair, but after the first treatment with IVIg, all dark hair fell out over 24-48 hours. As his symptoms of pandysautonomia were responding to treatment, he continued on IVIg and eventually received mycophenolate and pyridostigmine before transitioning to rituximab. Five years later, he remained without dark hair. No scalp biopsy was performed to assess for immunoglobulin deposition, and the patient had history of other autoimmune disorders, but the authors remind us that there have been prior, although rare reports of alopecia caused by IVIg.

Reduction in the white blood cell count is a side effect of many treatments and raises concern of an increased risk of infection. Fingolimod is used to treat MS and acts by inhibiting lymphocyte migration from lymph nodes resulting in a dose-dependent reduction of circulating lymphocytes. Reports have suggested that the use of fingolimod associates with a small increase in the risk of certain infections. Fox et al. ${ }^{7}$ reviewed the safety data from a phase 3 randomized, placebo-controlled trial evaluating the efficacy of fingolimod in patients with primary progressive MS to assess whether the reduction in absolute lymphocyte counts associated with an increased frequency of infections. They found that the mean absolute lymphocyte count of patients receiving fingolimod decreased by approximately $70 \%$ within 2 weeks after drug initiation and remained stable through the study. Over the 5 years that patients were clinically followed, the frequency and types of infections were similar in the fingolimod and placebo groups. There was also no association between the nadir or mean of the absolute lymphocyte count and the incidence of infection-related adverse events. The authors note that patients whose absolute lymphocyte counts dropped below the predefined threshold of $0.2 \times 10^{9} / \mathrm{L}$ had to discontinue the study drug until recovery of counts, and therefore, this study cannot fully assess the risk of infection for patients with counts below the indicated threshold. These interesting results support the safety of fingolimod and suggest that factors other than nadir or mean absolute lymphocyte count may associate with an increased risk of infection in patients with MS.

In addition to these studies, the November issue of N2 contains a comprehensive study on the prevalence of ANCAassociated vasculitis and associations with other organ manifestations by Bischof et al. ${ }^{8}$ and other interesting articles that I hope will catch your attention.

\section{Study funding}

No targeted funding reported.

\section{Disclosure}

Disclosures available: Neurology.org/NN.

\section{References}

1. Vogrig A, Fouret M, Joubert B, et al. Increased frequency of anti-Ma2 encephalitis associated with immune checkpoint inhibitors. Neurol Neuroimmunol Neuroinflamm 2019;6:e604. doi: 10.1212/NXI.0000000000000604.

2. Anand P, Hotan GC, Vogel AC, Nagagopal V, Matten F. Progressive multifocal leukoencephalopathy: A 25-year retrospective cohort study. Neurol Neuroimmunol Neuroinflamm 2019;6:e618. doi: 10.1212/NXI.0000000000000618.

3. Küpper C, Heinrich J, Kamm K, et al. Pembrolizumab for progressive multifocal leukoencephalopathy due to primary immunodeficiency. Neurol Neuroimmunol Neuroinflamm 2019;6:e628. doi: 10.1212/NXI.0000000000000628.

4. Pawlitzki M, Schneider-Hohendorf T, Rolfes $\mathrm{L}$, et al. Ineffective treatment of PML with pembrolizumab: Exhausted exhausted memory T-cell subsets as a clue? Neurol Neuroimmunol Neuroinflamm 2019;6:e627. doi: 10.1212/NXI.0000000000000627.

5. Du Pasquier RA. Pembrolizumab as a treatment for PML? Waiting for Godot. Neurol Neuroimmunol Neuroinflamm 2019;6:e629. doi: 10.1212/NXI.0000000000000629.

6. Turner L, Pittock S, McEvoy M, Flanagan E. Overnight loss of pigmented hair in autoimmune autonomic neuropathy treated with IVIg. Neurol Neuroimmunol Neuroinflamm 2019;6:e620. doi: 10.1212/NXI.0000000000000620.

7. Fox EJ, Lublin FD, Wolinsky JS, et al. Lymphocyte counts and infection rates: Longterm fingolimod treatment in primary progressive MS. Neurol Neuroimmunol Neuroinflamm 2019;6:e614. doi: 10.1212/NXI.0000000000000614.

8. Bischof A, Jaeger VK, Hadden RDM, et al. Peripheral neuropathy in antineutrophil cytoplasmic antibody-associated vasculitides: Insights from the DCVAS study. Neurol Neuroimmunol Neuroinflamm 2019;6:e615. doi: 10.1212/NXI.0000000000000615. 


\section{Neurology \\ Neuroimmunology \& Neuroinflammation}

Learning from adverse treatment effects

Josep Dalmau

Neurol Neuroimmunol Neuroinflamm 2019;6; 630

DOI 10.1212/NXI.0000000000000630

This information is current as of October 28, 2019

\section{Updated Information \& Services}

References

Permissions \& Licensing

Reprints including high resolution figures, can be found at:

http://nn.neurology.org/content/6/6/e630.full.html

This article cites 8 articles, 8 of which you can access for free at: http://nn.neurology.org/content/6/6/e630.full.html\#\#ref-list-1

Information about reproducing this article in parts (figures,tables) or in its entirety can be found online at:

http://nn.neurology.org/misc/about.xhtml\#permissions

Information about ordering reprints can be found online: http://nn.neurology.org/misc/addir.xhtml\#reprintsus

Neurol Neuroimmunol Neuroinflamm is an official journal of the American Academy of Neurology.

Published since April 2014, it is an open-access, online-only, continuous publication journal. Copyright

Copyright $\odot 2019$ The Author(s). Published by Wolters Kluwer Health, Inc. on behalf of the American Academy of Neurology.. All rights reserved. Online ISSN: 2332-7812.

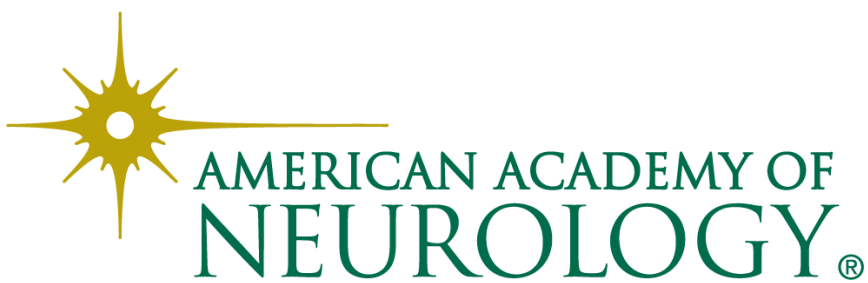

